Article

\title{
Study on the Anti-Biodegradation Property of Tunicate Cellulose
}

\author{
Yanan Cheng ${ }^{1}$, Ajoy Kanti Mondal ${ }^{1,2}$, Shuai $W_{u}{ }^{1}$, Dezhong Xu ${ }^{1}$, Dengwen Ning ${ }^{1}$, \\ Yonghao Ni ${ }^{1,3, *}$ and Fang Huang ${ }^{1, *}$ \\ 1 College of Material Engineering, Fujian Agriculture and Forestry University, Fuzhou 350108, China; \\ yanan.cheng@fafu.edu.cn (Y.C.); ajoymondal325@gmail.com (A.K.M.); dmxj0609@163.com (S.W.); \\ xudezhong95@163.com (D.X.); dengwen-ning@m.fafu.edu.cn (D.N.) \\ 2 Institute of Fuel Research and Development, Bangladesh Council of Scientific and Industrial Research, \\ Dhaka 1205, Bangladesh \\ 3 Department of Chemical Engineering, University of New Brunswick, Fredericton, NB E3B 5A3, Canada \\ * Correspondence: yonghao@unb.ca (Y.N.); fang.huang@fafu.edu.cn (F.H.)
}

Received: 3 November 2020; Accepted: 15 December 2020; Published: 21 December 2020

\begin{abstract}
Tunicate is a kind of marine animal, and its outer sheath consists of almost pure $\mathrm{I}_{\beta}$ crystalline cellulose. Due to its high aspect ratio, tunicate cellulose has excellent physical properties. It draws extensive attention in the construction of robust functional materials. However, there is little research on its biological activity. In this study, cellulose enzymatic hydrolysis was conducted on tunicate cellulose. During the hydrolysis, the crystalline behaviors, i.e., crystallinity index ( $\mathrm{CrI})$, crystalline size and degree of polymerization (DP), were analyzed on the tunicate cellulose. As comparisons, similar hydrolyses were performed on cellulose samples with relatively low $\mathrm{CrI}$, namely $\alpha$-cellulose and amorphous cellulose. The results showed that the $\mathrm{CrI}$ of tunicate cellulose and $\alpha$-cellulose was $93.9 \%$ and $70.9 \%$, respectively; and after $96 \mathrm{~h}$ of hydrolysis, the crystallinity, crystalline size and DP remained constant on the tunicate cellulose, and the cellulose conversion rate was below $7.8 \%$. While the crystalline structure of $\alpha$-cellulose was significantly damaged and the cellulose conversion rate exceeded $83.8 \%$ at the end of $72 \mathrm{~h}$ hydrolysis, the amorphous cellulose was completely converted to glucose after $7 \mathrm{~h}$ hydrolysis, and the DP decreased about $27.9 \%$. In addition, tunicate cellulose has high anti-mold abilities, owing to its highly crystalized $\mathrm{I}_{\beta}$ lattice. It can be concluded that tunicate cellulose has significant resistance to enzymatic hydrolysis and could be potentially applied as anti-biodegradation materials.
\end{abstract}

Keywords: tunicate cellulose; crystalline; enzymatic hydrolysis

\section{Introduction}

Cellulose is the most widely distributed, abundant and renewable polymer in nature. In the cellulose-degradation ecosystem, many cellulose-decomposing bacteria and fungi could hydrolyze insoluble cellulose substrates into soluble sugars, mainly cellobiose and glucose, which are then absorbed by cells. Generally, these microorganisms can produce various enzymes (i.e., cellulase), to catalyze the cellulose degradation. Cellulase is the general name of a group of enzymes, namely the endoglucanase, exogenous glucosidase and cellobiose. The synergistic effects of these enzymes induce the degradation of cellulose into monosugars.

Structural studies of cellulose show that cellulose is a homogeneous polycrystalline macromolecule compound. It contains crystalline and amorphous regions. In the crystalline region, the arrangement of cellulose molecules is completely regular. The connection between crystalline regions is amorphous regions, and there is no obvious boundary between crystalline and amorphous regions. The ratio of 
crystallization zone to the amorphous zone varies with the fiber types and the fiber locations. The physical and chemical properties of cellulose are closely related to its crystalline structures. Generally, the completely disordered amorphous region is more susceptible to the enzymatic hydrolysis than the regular crystalline regions. Therefore, understanding the crystallinity and morphology of cells plays an important role in enzymatic hydrolysis.

Cellulose can be found in plants (e.g., cotton, hemp and wood), marine animals (e.g., tunicates), algae (e.g., Valonia), bacteria (e.g., Acetobacterxylium) and even amoeba (Dictyosteliumdiscoideum) [1]. Even though they have the same chemical composition, their crystalline structures are significantly different, rendering them different physical and chemical properties. The tunicate cellulose is the only cellulose found so far from animals that is mainly in its capsule. The tough capsule mostly composed of cellulose and a small amount of proteins and inorganic compounds protecting the soft organs of the tunicate [2]. The tunicate cellulose is almost pure $\mathrm{I}_{\beta}$ crystalline cellulose. It has a unique monoclinic lattice, rendering it thermodynamically more stable than the triclinic lattice in cellulose $\mathrm{I}_{\alpha}$. In addition, the tunicate cellulose crystal has an exceptionally high ( $>70)$ length-to-diameter ratio (i.e., aspect ratio), indicating excellent mechanical properties [3].

Mainly due to its unique physical structures and chemical properties, intensive research has explored its applications on electrical- [4-7] and thermal-conductive [8], optical [9,10], and medical materials [11,12]. Furthermore, several studies were done to utilize cellulosic nanofibers in various fields, including the following: to remove heavy metal ions and degrade dye from water [13-15]; as an electrochemical energy storage devices [15-17]; as reinforced polymer composites [15]; and as cosmetic products, wound dressings, drug carriers, medical implants, tissue engineering, food and composites $[15,18]$.

However, there is little research in the literature on the biological activity of tunicate cellulose. In this study, the enzymatic hydrolysis and anti-mold experiments were conducted on tunicate cellulose. During the hydrolysis, the variations of cellulose crystallinity, crystal size and degree of polymerization were extensively evaluated. As comparisons, similar hydrolysis were performed on cellulose samples with a relatively low crystallinity index $(\mathrm{CrI})$, namely $\alpha$-cellulose and amorphous cellulose. In the anti-mold experiments, different percentages of tunicate nanocrystals were mixed in the cultivated medium, and the mold growth rates were monitored. The objective of this research was to establish the relationship between the tunicate cellulose crystalline structure and its anti-biodegradation properties. As far as we know, this is the first research on the biodegradation properties of marine animal (tunicate) cellulose. This research should surely be helpful to extend the application of tunicate cellulose in the biological domain.

\section{Materials and Methods}

\subsection{Materials}

Red reef tunicates (Rhopalaeaabdominalis) were purchased from Weihai Sea Food Market in Shandong, China. The mold strain (Aspergillusniger) and the modified Martin agar medium were purchased from DATA Laboratory Equipment Reagent (Tianjin, China). The cellulose enzyme was kindly donated by Vland Biotech (Qingdao, China). The radiate pine dissolving pulp was donated by Qingshan Paper (Fujian, China). All the chemicals used in this study, including $\mathrm{KOH}, \mathrm{KBr}, \mathrm{HCl}$, $\mathrm{H}_{2} \mathrm{SO}_{4}, \mathrm{NaClO}_{2}, \mathrm{CH}_{3} \mathrm{ONa}, \mathrm{CH}_{3} \mathrm{OH}, \mathrm{C}_{3} \mathrm{H}_{7} \mathrm{OH}$, uranyl acetate and acetate buffer, were of analytical grade and were procured from Beijing Inno Chem Science \& Technology Co. Ltd (Beijing, China).

\subsection{Methods}

\subsubsection{Preparation of Tunicate Cellulose}

The tunicate specimens were slit open with the help of a sharp knife, and their mantles were washed thoroughly under deionized water. Whole mantles were soaked for a whole night, in a $5(\% \mathrm{w} / \mathrm{v})$ 
aqueous $\mathrm{KOH}$ solution, at normal temperature. The mantles were then rinsed with DI water and bleached for $6 \mathrm{~h}$ at $70^{\circ} \mathrm{C}$, with a bleaching solution, exchanging the used bleaching solution with a fresh one every $2 \mathrm{~h}$. Then, $300 \mathrm{~mL} 2 \%(6 \mathrm{~g})$ chlorite solution and $5 \mathrm{~mL}$ of anhydrous (water-free) acetic acid were mixed properly, to make bleaching solution. These treatments, i.e., the adding of $\mathrm{KOH}$, followed by bleaching, were repeated four times, until the mantles became completely white. At last they were washed thoroughly and cut into small pieces, for further characterizations.

\subsubsection{Preparation of Amorphous Cellulose}

Purified fibrous cotton hydrocellulose $(1.0 \mathrm{~g})$ and DMSO $(100 \mathrm{~mL})$ were mixed by stirring at $125^{\circ} \mathrm{C}$. Then paraformaldehyde $(5.0 \mathrm{~g})$ was added into the mixture, and stirring was carried on until a clear solution was acquired, and the methyl cellulose solution was diluted with DMSO $(400 \mathrm{~mL})$ and allowed to cool down at normal temperature. After that, the solution was filtered through $1.2 \mu \mathrm{m}$ glass microfiber. The solution of $0.2 \mathrm{~mol} / \mathrm{L}$ sodium alkoxide in methanol:2-propanol (1:1, vol: $2 \mathrm{~L}$ ) was added, dropwise, to the stirred regeneration bath. The cellulose precipitate was washed with $0.2 \mathrm{~mol} / \mathrm{L}$ sodium alkoxide in methanol:2-propanol (1:1, vol: $600 \mathrm{~mL})$, methanol $(3 \times 600 \mathrm{~mL}), 0.1 \mathrm{~mol} / \mathrm{L} \mathrm{HCl}$ $(600 \mathrm{~mL})$, distilled water $(3 \times 600 \mathrm{~mL}), 0.1 \mathrm{~mol} / \mathrm{L} \mathrm{HCl}(600 \mathrm{~mL})$ and distilled water $(3 \times 600 \mathrm{~mL})$ and then freeze-dried prior to use.

\subsubsection{Preparation of Softwood $\alpha$-Cellulose}

The $\alpha$-cellulose was prepared from the dissolving pulp, following the literature method [19]. At first, pulp samples were treated with $17.5 \% \mathrm{NaOH}$ solution at $20^{\circ} \mathrm{C}$ for $45 \mathrm{~min}$, to remove the hemicellulose. Most of the non-cellulosic carbohydrates were dissolved in the basic solution, and the cellulose was insoluble. The solid residue was washed with DI water, until neutral. The retained solid cellulose was denoted as $\alpha$-cellulose.

\subsubsection{Enzymatic Hydrolysis of Cellulose Samples}

Cellulose samples were hydrolyzed by using a commercial enzyme (cellulase and cellobiose). The activity of cellulase was 103.3 FPU determined by the NREL method [20]. Enzymatic hydrolysis of cellulose substrates was carried on at $5 \%(w / v)$, in $50 \mathrm{~mL}$ of $50 \mathrm{mM}$ acetate buffer (pH 4.8), in an incubator shaker (IS-RDH1, Jiangsu Taicang equipment factory, China), at $45^{\circ} \mathrm{C}$, with rotation speed of $150 \mathrm{rpm}$. The substrate was put on the incubation shaker for $10 \mathrm{~min}$ with buffer mixtures, following the adding of enzymes. Enzymatic hydrolysis was halted by boiling the sample for $5 \mathrm{~min}$, to inactivate the enzyme activities. Liquid samples were extracted and filtered at various time intervals, for the sugar-release analysis. All of the extracted liquid samples were further analyzed for glucose content by high-performance ion-exchange chromatography with pulsed amperometric detection (HPAEC-PAD, Dionex IC 3000, USA). The cellulose conversion rate (\%) was calculated as Equation (1) [21]:

$$
\text { Cellulose conversion rate }=\frac{0.9 \times 100 \times \text { glucose }(g)}{\text { Initial cellulose }(g)}
$$

The solid residue (non-hydrolyzed solid) was extensively washed with DI water, to remove non-adsorbed enzymes. After that, the samples were air-dried for the XRD analysis.

\subsubsection{Characterization}

$\mathrm{XRD}$

The crystallinity was evaluated by using the XRD patterns that were recorded by X-ray diffractometer Rigaku RINT 2200 equipped with monochromator, which is an important method to study the ultrafine properties of cellulose. It is the most direct method for analyzing the cellulose crystalline structure and crystal orientations. X-ray diffraction was conducted on reflectance modes 
through $7.5^{\circ}<2 \theta<32.5^{\circ}$ by $\mathrm{Cu}-\mathrm{K} \alpha$ radiation, operated at $40 \mathrm{kV}$ and $30 \mathrm{~mA}$. The cellulose crystallinity was measured by deconvolution method as previously reported [22]. The cellulose crystallization index, crystallinity and crystal size were characterized based on X-ray diffraction patterns and peak-splitting results.

The crystallization index ( $\mathrm{CrI}$ ) was calculated according to Segal [23] Equation (2).

$$
C r I=\frac{I_{c r}-I_{a m}}{I_{c r}} \times 100 \%
$$

where $I_{c r}$ is maximum diffraction intensity of 002 surface (for cellulose I) or $10 \overline{1}$ surface (for cellulose II), and $I_{a m}$ is diffraction intensity in amorphous region.

The crystal size can be calculated according to Scherer [24] method, according to Equation (3).

$$
I_{h k I}=\frac{K \lambda}{\beta \cos \theta}
$$

where $I_{h k l}$ is the crystal size, $K$ is the Sherrow constant $(K=0.9, \lambda=0.1542 \mathrm{~nm})$ and $\beta$ is the maximum half-width of the characteristic diffraction peak, expressed in radian.

\section{Degree of Polymerization}

Gel permeation chromatography (GPC) (Waters, Polymer Standards Service, Milford, CT, USA) was used to determine the weight average molecular weight $\left(M_{w}\right)$ distribution and degree of polymerization (DP) of cellulose samples. At first, the cellulose samples were derivatized by phenyl isocyanate according to the published literature method $[25,26]$. From each sample, $15.0 \mathrm{mg}$ of cellulose was taken in test tubes outfitted with micro stir bars, and it was vacuum-dried overnight, at $40^{\circ} \mathrm{C}$. Then anhydrous pyridine $(4.00 \mathrm{~mL})$ and phenyl isocyanate $(0.50 \mathrm{~mL})$ were added, and the test tubes were capped properly with rubber septa. To complete the reaction, the test tubes were kept in an oil bath, with continuing stirring, for $72 \mathrm{~h}$. The reaction was stopped by adding of $1.00 \mathrm{~mL}$ of $\mathrm{CH}_{3} \mathrm{OH}$, and, later, the resulting mixture was added dropwise to a $7: 3 \mathrm{CH}_{3} \mathrm{OH} / \mathrm{H}_{2} \mathrm{O}$ solution $(100.0 \mathrm{~mL})$, so that the precipitation of derivatized cellulose could be promoted. Solid products were collected by filtration and thoroughly washed with $\mathrm{CH}_{3} \mathrm{OH} / \mathrm{H}_{2} \mathrm{O}$ solution $(1 \times 50.0 \mathrm{~mL})$ and later with $\mathrm{H}_{2} \mathrm{O}(2 \times 50.0 \mathrm{~mL})$. Finely washed derivatized cellulose was dried overnight, under vacuum, at $40^{\circ} \mathrm{C}$. GPC analysis was performed by dissolving the derivatized cellulose in tetrahydrofuran $(2 \mathrm{mg} / \mathrm{mL})$, followed by filtering through a $0.22 \mu \mathrm{m}$ filter and then being placed in a $2 \mathrm{~mL}$ auto-sampler vial.

\section{FTIR Analysis}

The FTIR spectra were acquired by using the $\mathrm{KBr}$ pellet technique. A very tiny amount of sample was mixed with $\mathrm{KBr}(1 \mathrm{mg}$ sample $/ 100 \mathrm{mg} \mathrm{KBr})$ and grinded in an agate mortar. A pellet of the grinding mixture was prepared by pressing with hydraulic pressure. Spectra were registered by using the VERTEX 70 spectrometer (Bruker, Billerica, MA, USA), at the range from 4000 to $450 \mathrm{~cm}^{-1}$, at a resolution of $4 \mathrm{~cm}^{-1}$.

\subsubsection{Anti-Mold Experiment}

In order to perform the anti-mold experiment, the substrate should be evenly dispersed in the agar medium. The tunicate cellulose prepared in Section 2.2.2 was in the form of flakes, while the softwood $\alpha$-cellulose prepared in Section 2.2.3 was in big particles. Evidently, it is difficult to disperse these two celluloses in the cultivated medium. To solve this problem, the tunicate cellulose and softwood $\alpha$-cellulose were hydrolyzed to cellulose nanocrystals by $\mathrm{H}_{2} \mathrm{SO}_{4}$, as described in the preparation of cellulose nanocrystals. In addition, XRD analysis was performed on these cellulose nanocrystals, with the aim of checking the $\mathrm{CrI}$ changes during the acid hydrolysis. The anti-mold experiments were only 
conducted on the tunicate and softwood nanocrystals. The amorphous cellulose was excluded from the experiment because of its poor anti-biodegradations.

Preparation of Cellulose Nanocrystals

Cellulose nanocrystals were prepared by acid hydrolysis process of softwood pulp, following the literature method [27]. In brief, $60.0 \mathrm{~g}$ of oven dried pulp was mixed with $\mathrm{H}_{2} \mathrm{SO}_{4}(64 \%$, w/w, $1: 10 \mathrm{~g} / \mathrm{mL}$ ) solution at $45^{\circ} \mathrm{C}$ and stirring continuously for about $45 \mathrm{~min}$. An excess amount (10-fold) of distilled water was added in the solution, to stop the hydrolysis reaction. To remove acid and water from the solution, it was centrifuged at 12,000 rpm for $10 \mathrm{~min}$, until the supernatant became turbid. The sediment containing nanocellulose was collected and dialyzed (MWCO: 12-14,000) against tap water, until the solution $\mathrm{pH}$ became neutral. The content after dialysis was sonicated for $10 \mathrm{~min}$ and centrifuged again, at 10,000 rpm, for $5 \mathrm{~min}$. The cloudy supernatant, containing nanocellulose, was collected, and the remaining sediment was again mixed with water, sonicated and centrifuged to obtain extra nanocellulose, and this process was repeated till the supernatant was clear.

\section{TEM Analysis of Prepared Softwood Cellulose Nanocrystal}

Transmission electron microscopy (TEM) was used to measure the dimensions of the prepared cellulose nanocrystals. From the nanocrystal suspension ( $1 \mathrm{wt} \%)$, one drop was accumulated on the surface of a tidy copper grid covered with a porous thin carbon film. A drop of a diluted suspension was deposited on the surface of a clean copper grid covered with a porous thin carbon film. The samples were then stained by allowing the grids to float in a $2 \mathrm{wt} \%$ solution of uranyl acetate for $3 \mathrm{~min}$. At last, the samples were dried at room temperature, for $24 \mathrm{~h}$. The grid was analyzed in a TECNAI G2 F20TEM (US FEI Co.), with $0.2 \mathrm{~nm}$ resolution. The length and width of prepared cellulose nanocrystals were measured by using the software Gatan Digital Micrograph.

\section{Anti-Mold Effect of Cellulose Nanocrystals}

Prior to use, the mold (Aspergillusniger) should be activated in the medium. The activation was performed according to the following procedures. Briefly, the strain was inoculated onto the modified Martin agar medium and cultured in a biochemical incubator, at $26^{\circ} \mathrm{C}$, for one week $[28,29]$. The medium and tunicate cellulose nanocrystals were sterilized at $121^{\circ} \mathrm{C}$ for $20 \mathrm{~min}$. The medium and tunicate cellulose nanocrystals were thoroughly mixed according to the dry weight ratio of $0 \%, 10 \%$, $30 \%, 50 \%, 80 \%$ and $100 \%$, to prepare a flat plate. In the center of each plate, a hole of $0.7 \mathrm{~cm}$ in diameter was drilled to receive activated mold strain by a hole punch tool [30]. Then the activated mold cake with the same diameter was transferred to the hole, by using the same tool. The flat plate was then cultivated in a biochemical incubator, at $26^{\circ} \mathrm{C}$. The radius of mold growth was measured after 12,24 , $36,48,60$ and $72 \mathrm{~h}$, respectively. In order to compared the anti-mold ability of tunicate celluloses with other cellulose samples, a similar medium ( $50 \mathrm{wt} \%$ ) was mixed with $\alpha$-cellulose nanocrystals (50 $\mathrm{wt} \%$ ), to perform the same experiments. In addition, a blank sample was donated as the pure Martin agar medium in the cultivation.

\section{Growth Rate Analysis}

Due to the uneven growth of mold, the radius of different mold growth was measured from the top, bottom, left and right directions (Figure 1). The growth rate of mold was calculated by the following equations.

$$
\mathrm{r}=\frac{r_{\text {top }}+r_{\text {bottom }}+r_{\text {left }}+r_{\text {down }}}{4}
$$


where $r_{\text {top }}, r_{\text {bottom }}, r_{\text {left }}$ and $r_{\text {right }}$ are the radius (mm) measured from the top, bottom, left and right directions, and " $\mathrm{r}$ " refers to average growth radius ( $\mathrm{mm})$.

$$
\text { Growth rate }=\frac{\Delta r_{t}}{\Delta t}
$$

where $\Delta t$ is the cultivation time (h), and $\Delta r_{t}$ is the growth radius at $\Delta t$ (h) time period.
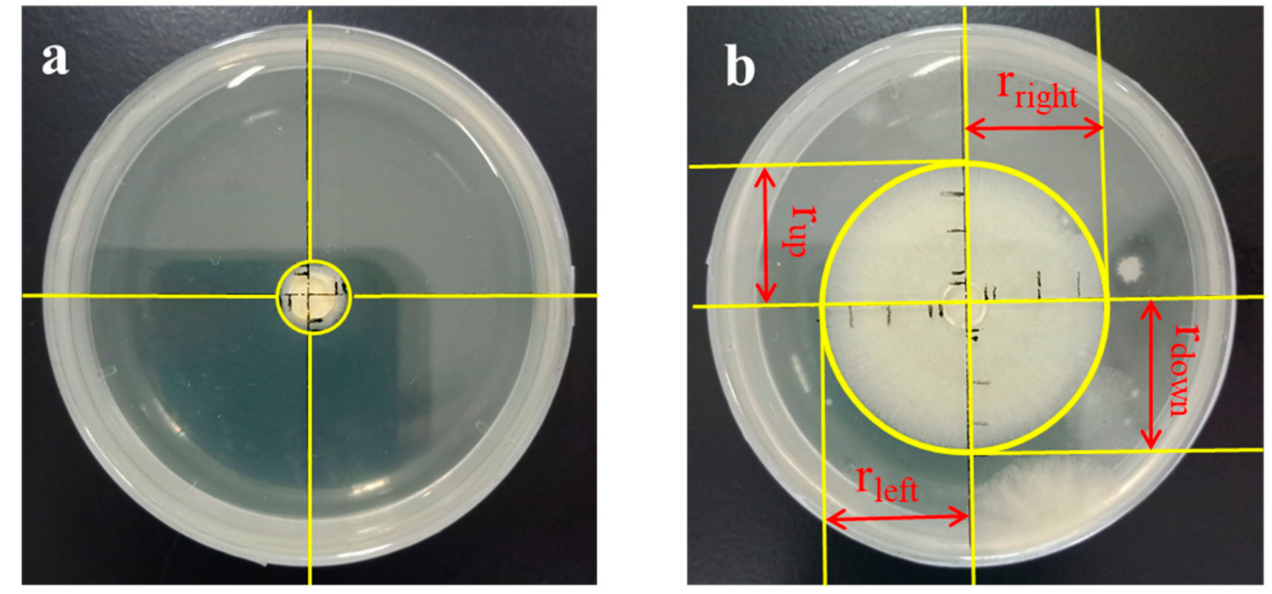

Figure 1. Anti-mold experiment process of tunicate cellulose: (a) initial growth of mold and (b) growth of mold at time, $\mathrm{t}$.

\subsection{Error Analysis}

Triple measurements were conducted for all the characterization techniques, and a mean value was reported. The error margin associated with all the analysis was within $\pm 2.5 \%$.

\section{Results and Discussion}

\subsection{XRD Analysis}

Cellulosic compounds have both crystalline and amorphous region, and XRD analyses were performed to identify the crystalline and amorphous structure [31,32]. In order to systematically analyze the cellulose crystal patterns, the Gauss function in origin 9.1 software was used to separate the XRD intensity peaks, aiming to identify the cellulose crystal lattice planes. Figures $2-4$ represent the XRD patterns of tunicate cellulose, $\alpha$-cellulose and amorphous cellulose samples, respectively. The XRD analyses on the cellulose $C r I$ and $I_{h k l}$ (crystallite size) are listed in Table 1. Figures 2a and 3a, show the original diffraction patterns of $X R D$, and the Figures $2 b$ and $3 b$ represent the peak separations. It can be clearly seen that both the tunicate cellulose and $\alpha$-cellulose have typical (101), (101) and (002) lattice planes in XRD patterns. Tunicate cellulose show the peak values of the position at $2 \theta=22.9^{\circ}$, $16.6^{\circ}$ and $14.8^{\circ}$ for the typical (002), (101) and (101) lattice planes, respectively. These results indicate that prepared tunicate cellulose has a good crystalline structure, which is the good agreement of the published literature [33]. The XRD peak fitting indicated that the $C r I$ and crystalline size $\left(I_{h k l}\right)$ of tunicate cellulose areas were as high as $93.9 \%$ and $9.3 \mathrm{~nm}$, respectively, as shown in Table 1 . These data were close to the literature report [34]. The narrow and sharp diffraction peak at 22.9 (Figure 2) also indicated the excellent crystalline structure of tunicate cellulose [35]. 


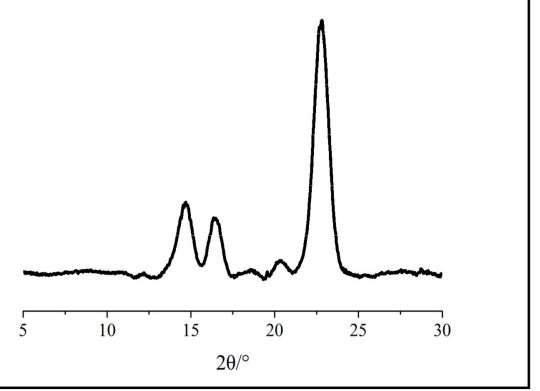

b

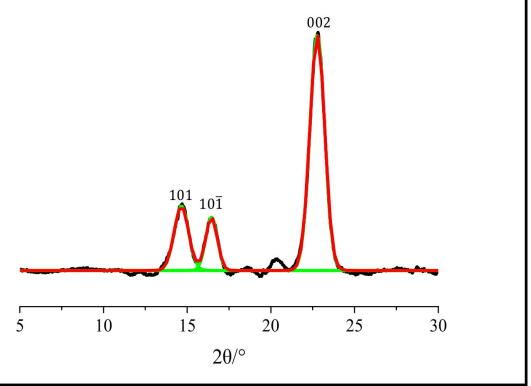

Figure 2. XRD patterns of tunicate cellulose: (a) original XRD pattern and (b) peak separation results.
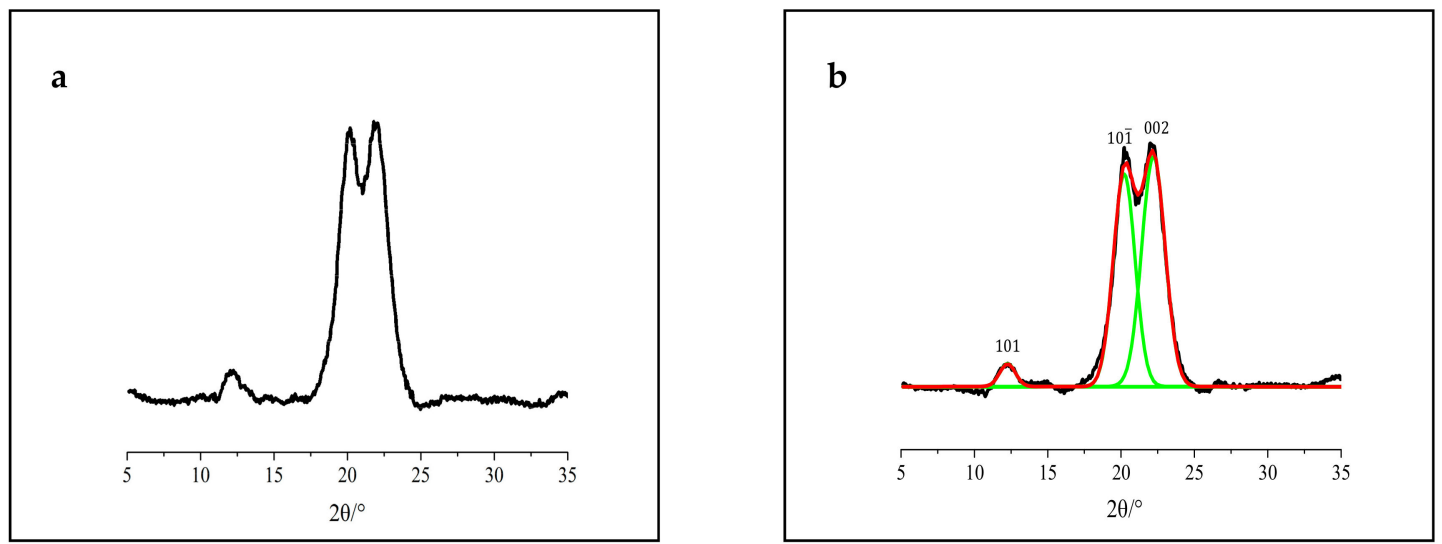

Figure 3. XRD patterns of $\alpha$-cellulose: (a) original XRD patterns and (b) peak separation results.

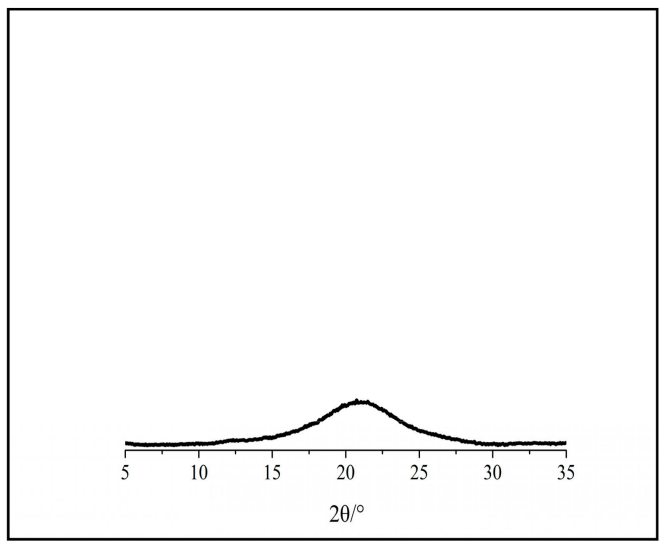

Figure 4. Patterns of amorphous cellulose.

Table 1. XRD analysis of the cellulose crystallinity index $(\mathrm{Cr} I)$ and crystallite size $\left(I_{h k l}\right)$.

\begin{tabular}{ccc}
\hline Cellulose Sample & $\boldsymbol{C r I} \mathbf{( \% )}$ & $\boldsymbol{I}_{\boldsymbol{h k l}}$ Crystallite Size (nm) \\
\hline Tunicate cellulose & 93.9 & 9.3 \\
$\boldsymbol{\alpha}$-cellulose & 70.9 & 2.1 \\
amorphous cellulose & - & - \\
\hline
\end{tabular}

Figure 3 shows the $\alpha$-cellulose crystal pattern, and the peaks value at the position of (101), (101) and (002) lattice planes are $2 \theta=12.1^{\circ}, 20.2^{\circ}$ and $22.1^{\circ}$, respectively. Moreover, $\alpha$-cellulose is semi-crystalline in nature. The peak values at the position of $2 \theta=20.2^{\circ}$ and $15.0^{\circ}$ represent the crystalline and amorphous structure, respectively [36,37]. Similar results were reported for the characterization of $\alpha$-cellulose [38]. The XRD peak fitting of $C r I$ and crystalline size $\left(I_{h k l}\right)$ for $\alpha$-cellulose is $70.9 \%$ and 
$2.1 \mathrm{~nm}$, respectively, as shown in Table 1 . These measurements were in agreement with the literature data [34].

Figure 4 demonstrates the amorphous cellulose, indicating the absence or strong reduction of all peaks corresponding to crystal lattice planes (101), (10 $\overline{1}$ ) and (002). A broaden peak shows at $2 \theta=21^{\circ}$ region, indicating the typical amorphous cellulose structure $[22,39,40]$. The amorphous cellulose did not show any crystallite structures, as indicated in Table 1.

\subsection{FTIR Analysis}

Figure 5 represents the FTIR spectra of $\alpha$-, amorphous and tunicate celluloses. The transmittance bands are detected in two wave number regions of $3700-2500 \mathrm{~cm}^{-1}$ and $1750-500 \mathrm{~cm}^{-1}$. The transmittance band in pulp $\alpha$-cellulose and amorphous cellulose was observed at the range of $3700-2900 \mathrm{~cm}^{-1}$, corresponding to the vibrational stretching of hydrogen bonded O-H and C-H bonds in polysaccharides. A broad transmittance band at around $3409 \mathrm{~cm}^{-1}$ is represented to the characteristic vibrational stretching of hydroxyl group in polysaccharides [41,42]. This band also indicates the intra- and inter-molecular hydrogen bond vibrations in cellulose [43]. The transmittance band near $2904 \mathrm{~cm}^{-1}$ is assigned to the $\mathrm{C}-\mathrm{H}$ stretching vibration of all hydrocarbon components in polysaccharides $[42,44]$. Typical peaks attributed to cellulose were detected in the range of $1630-900 \mathrm{~cm}^{-1}$. The bands located at $1638 \mathrm{~cm}^{-1}$ match to $\mathrm{O}-\mathrm{H}$ bending vibration of water molecules absorbed in cellulose [45]. The transmittance peaks at $1057 \mathrm{~cm}^{-1}$ belong to stretching vibrations of C-O and C-C bonds in cellulose $[45,46]$.

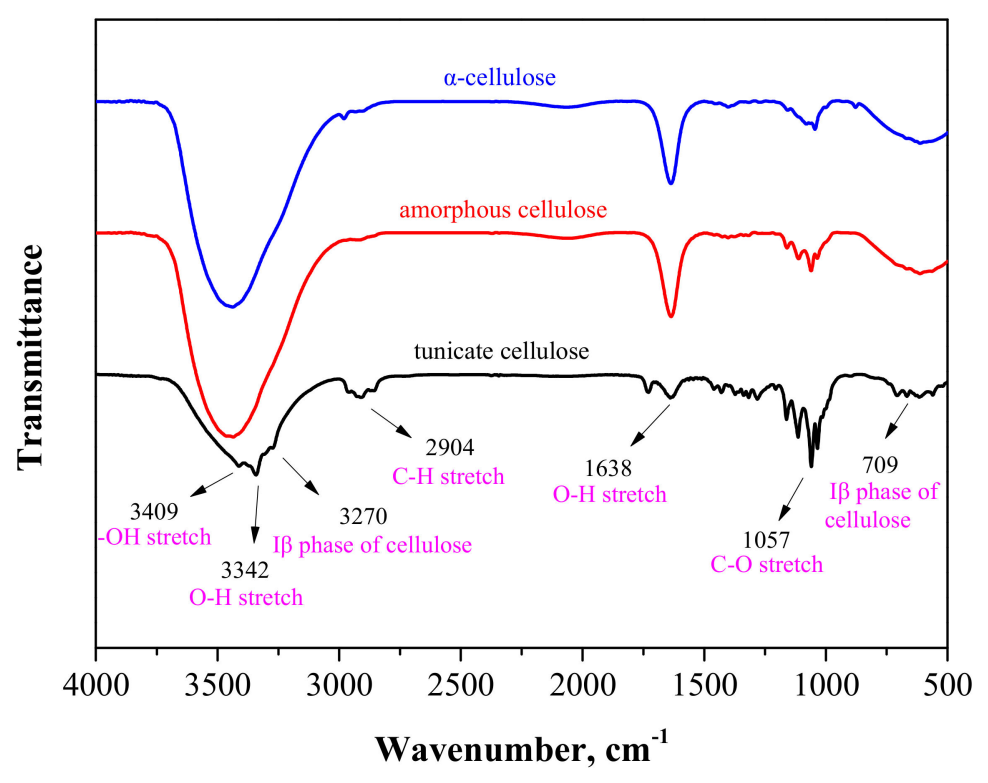

Figure 5. FTIR spectra of tunicate, pulp $\alpha$ and amorphous cellulose.

Figure 5 illustrates that tunicate cellulose shows the typical characteristics transmittance of cellulose for the stretching vibrations of O-H, C-H and C-O at 3342, 2904 and $1057 \mathrm{~cm}^{-1}$, respectively [45]. Two transmittance bands near 3270 and $709 \mathrm{~cm}^{-1}$ in tunicate cellulose indicated the $\mathrm{I}_{\beta}$ phase of cellulose [41], whereas these bands are absent in $\alpha$-cellulose and amorphous cellulose. These two peaks clearly proved that tunicate cellulose has and $\mathrm{I}_{\beta}$ crystalline structure.

\subsection{XRD Analysis of Cellulose after Enzymatic Hydrolysis}

In order to investigate the biological activity of tunicate cellulose under the action of enzymes, enzymatic hydrolysis of tunicate cellulose, $\alpha$-cellulose and amorphous cellulose was carried out. Wide-angle X-ray diffraction (WAXD) scanning was accomplished in the range of $2 \theta=5 \sim 35^{\circ}$ for the tunicate and $\alpha$-celluloses. Figure 6 shows the XRD patterns of the tunicate cellulose after enzymatic 
hydrolysis of different time intervals $(0,12,24,48,72$ and $96 \mathrm{~h})$. It can be seen that the intensity of $2 \theta=22.9^{\circ}$ is almost unchanged between the initial hydrolysis stage and different time intervals $(0,12$, $24,48,72$ and $96 \mathrm{~h}$ ). The peak values of the position at $2 \theta=14.8^{\circ}, 16.6^{\circ}$ and $20.3^{\circ}$ are the same even after different hydrolysis time intervals. Tunicate cellulose has a highly crystalline structure (Figure 2), as compared to $\alpha$-cellulose and amorphous cellulose, rendering it stable in enzymatic hydrolysis and causing it to retain its crystal structure up to $96 \mathrm{~h}$. The crystal structure of tunicate cellulose forms a physical barrier to the enzyme, resulting its intact crystal lattice in the XRD pattern [47].

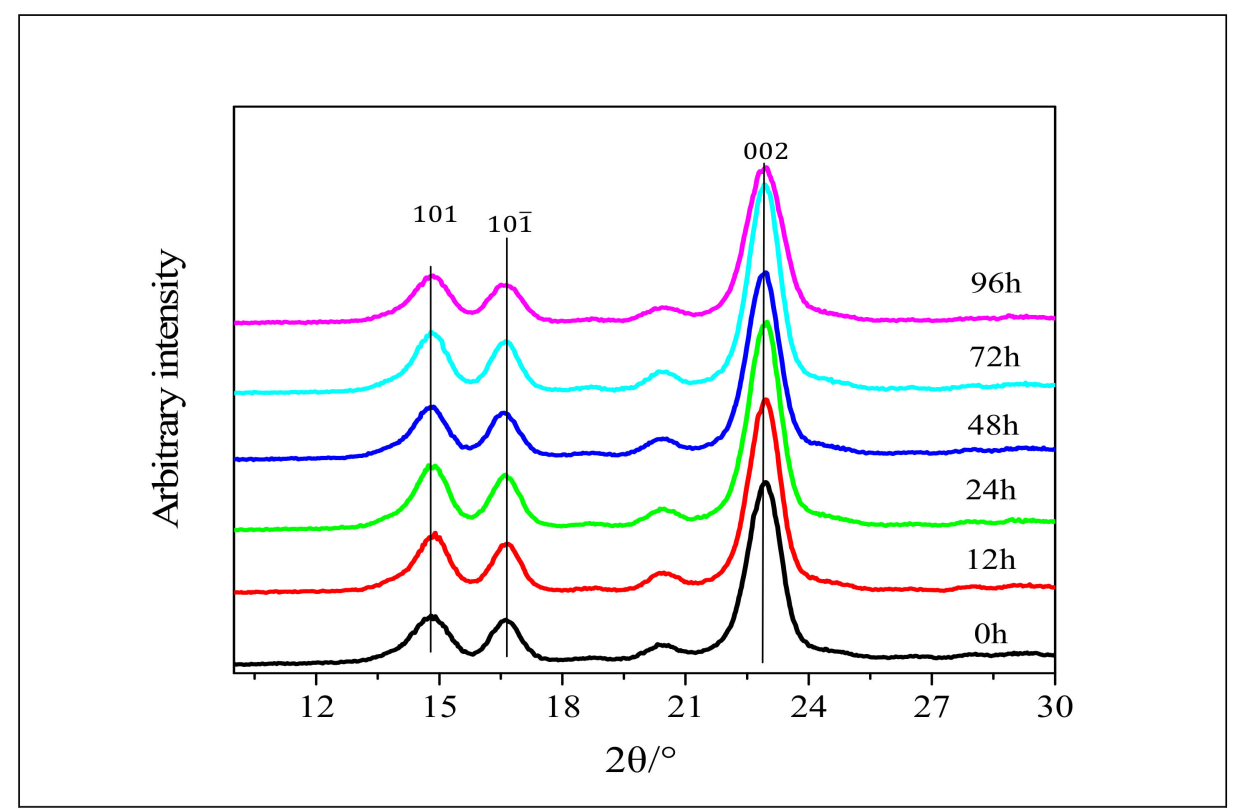

Figure 6. The XRD pattern of tunicate cellulose after enzymatic hydrolysis.

Figure 7 shows the XRD patterns of $\alpha$-cellulose after enzymatic hydrolysis of different time intervals $(0,12,24,48,72,96 \mathrm{~h})$, and some significant changes were observed at different stages. The strengths at the position of $2 \theta=20.2^{\circ}$ and $22.1^{\circ}$ are gradually increased with the prolongation of hydrolysis time. Moreover, $\alpha$-cellulose has both crystalline and amorphous regions in the cellulose structure. The amorphous region is unstable and is easily degraded during enzymatic hydrolysis [48]. Compared with the amorphous regions, the crystal regions are more resistant to the enzyme hydrolysis. As a result, with the decrease of amorphous regions, the peaks of crystal lattices (10 $\overline{1}$ and 002$)$ become more and more prominent during the hydrolysis [49-52].

\subsection{Effects of Enzymatic Hydrolysis on CrI and Average Crystal Size of Cellulose}

The $C r I$ and average crystal size $\left(I_{h k l}\right)$ of tunicate cellulose and $\alpha$-cellulose after enzymatic hydrolysis are represented in Figures 8 and 9. During the enzymatic hydrolysis of, it was observed that the change of $\mathrm{CrI}$ for the tunicate cellulose (Figure 8) was little. The CrI fluctuated between $93.2 \%$ and $94.9 \%$. Moreover, the crystalline sizes $\left(I_{h k l}\right)$ were almost the same. This is mainly due to its unique $\mathrm{I}_{\beta}$ crystal cell structure: monoclinic cell with two chains, which render it a high density and make it thermodynamically and chemically stable [53-55]. 


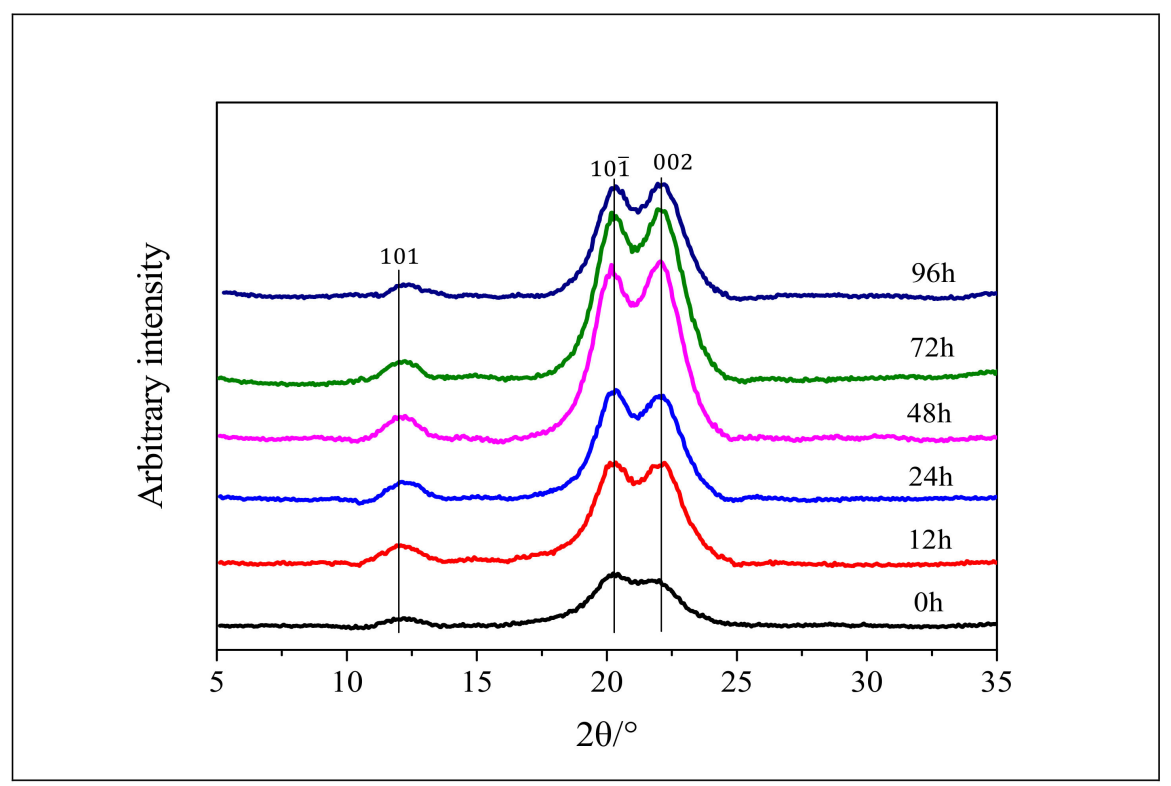

Figure 7. The XRD pattern of $\alpha$-cellulose after enzymatic hydrolysis.

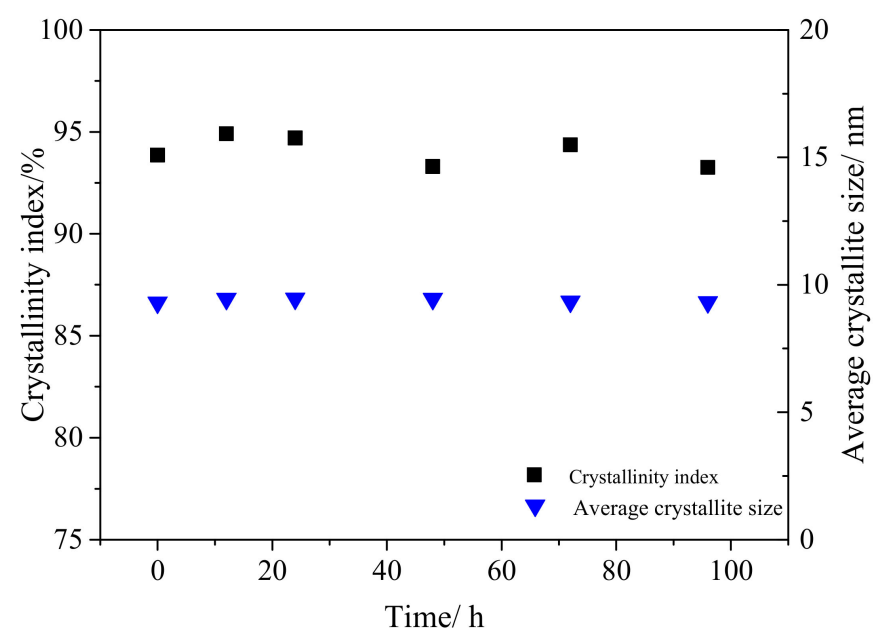

Figure 8. The variations of $\mathrm{CrI}$ and average crystallite size $\left(I_{h k l}\right)$ of tunicate cellulose during the enzymatic hydrolysis.

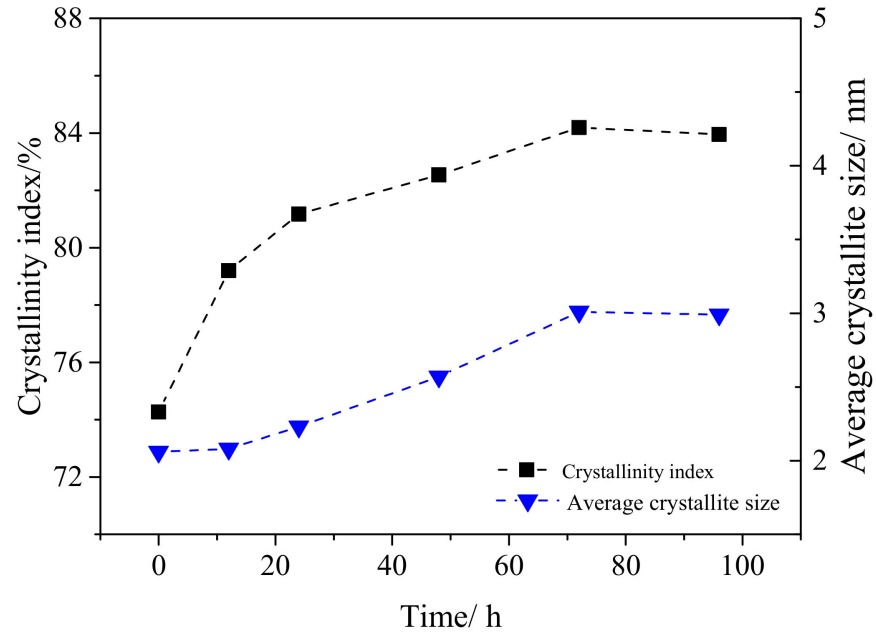

Figure 9. The variations of $C r I$ and average crystallite size $\left(I_{h k l}\right)$ of $\alpha$-cellulose during the enzymatic hydrolysis. 
Compared with the tunicate cellulose, the trend of $\mathrm{CrI}$ of $\alpha$-cellulose (Figure 9) is totally different during the hydrolysis. The CrI increased first and then tended to be flat. The highest $\mathrm{CrI}(84.2 \%)$ was achieved at $72 \mathrm{~h}$ hydrolysis. As indicated in Figure 3, the $\alpha$-cellulose consisted of amorphous and crystal regions in the cellulose structure. During the initial stage of hydrolysis, the amorphous region was likely to be degraded and hydrolyzed by the enzyme. On the contrary, the crystal region showed higher resistance to the enzyme attack [56]. As a result, the $\mathrm{CrI}$ decreased rapidly in the initial hydrolysis stage (0-24 h), following a slow decrease during the subsequent hydrolysis (24-96 h). Besides the $\mathrm{CrI}$, the crystalline size of $\alpha$-cellulose showed the same tendency as the CrI, indicating that the small cellulose crystals were vulnerable and were preferably hydrolyzed during the enzymatic hydrolysis. In addition, the crystal structure of $\alpha$-cellulose is cellulose $\mathrm{I}_{\alpha}$ type. Compared with $\mathrm{I}_{\beta}$ cellulose (monoclinic with two chains), $\mathrm{I}_{\alpha}$ cellulose has triclinic cell with one chain. This structure renders it a lower density and makes it less chemically stable [1].

\subsection{Degree of Polymerization}

Molecular weight $\left(M_{w}\right)$ and degree of polymerization (DP) of tunicate cellulose, $\alpha$-cellulose and amorphous cellulose are represented in Table 2. Results indicate that similar $M_{w}\left(\sim 2.48 \times 10^{6} \mathrm{~g} / \mathrm{mol}\right)$ and DPs ( 4800) were exhibited during the hydrolysis. The variation between highest $M w$ and DP (appeared at $0 \mathrm{~h}$ ) and the lowest $M_{w}$ and DP (appeared in $96 \mathrm{~h}$ ) was only $1.04 \%$. This tendency was in accordance with the $\mathrm{CrI}$ measurement in Figure 8. Again, thanks to its extremely high $\mathrm{CrI}$ and solid $\mathrm{I}_{\beta}$ crystal lattice structure, the tunicate cellulose showed excellent ability of anti-biodegradation during the enzymatic hydrolysis. As for the case of $\alpha$-cellulose, the values of $M_{w}$ and DP of $\alpha$-cellulose are $1 / 6$ time of tunicate cellulose. In addition, the $M_{w}$ and DP of $\alpha$-cellulose were continuously decreased with the increase of hydrolysis time. Compared with the beginning of hydrolysis at $0 \mathrm{~h}$, the $M_{w}$ and $\mathrm{DP}$ at $96 \mathrm{~h}$ were decreased by $20.8 \%$. As discussed earlier, $\alpha$-cellulose contained amorphous region, and its crystal lattice was $\mathrm{I}_{\alpha}$ type, which were both less resistant to enzymatic attack, compared with tunicate $\mathrm{I}_{\alpha}$ crystal lattice. As for the amorphous cellulose, the $M_{w}$ and DP decreased rapidly, by $27.9 \%$, only after $7 \mathrm{~h}$ of hydrolysis. Furthermore, the amorphous cellulose was completely dissolved in the hydrolysis solution at that time. As a result, there were no $M_{w}$ and DP data for the amorphous cellulose after $7 \mathrm{~h}$. In summary, during the enzymatic hydrolysis, the tunicate cellulose showed the highest, and the amorphous cellulose showed lowest, resistance to the biodegradation. The ability of $\alpha$-cellulose was in between.

Table 2. Molecular weight $\left(M_{w}\right)$ and polymerization degree of tunicate cellulose, $\alpha$-cellulose and amorphous cellulose at different enzymatic hydrolysis stages.

\begin{tabular}{cccc}
\hline Sample & Hydrolysis Time/h & $\boldsymbol{M}_{\boldsymbol{w}}(\mathrm{g} / \mathbf{m o l})$ & DP \\
\hline \multirow{4}{*}{ tunicate cellulose } & 0 & $2.504 \times 10^{6}$ & 4824 \\
& 24 & $2.493 \times 10^{6}$ & 4803 \\
& 48 & $2.492 \times 10^{6}$ & 4801 \\
& 72 & $2.489 \times 10^{6}$ & 4795 \\
& 96 & $2.488 \times 10^{6}$ & 4793 \\
$\alpha$-cellulose & 0 & $2.478 \times 10^{6}$ & 4774 \\
\hline & 12 & $4.650 \times 10^{5}$ & 896 \\
& 24 & $4.489 \times 10^{5}$ & 865 \\
& 48 & $4.437 \times 10^{5}$ & 855 \\
& 72 & $3.778 \times 10^{5}$ & 728 \\
& 96 & $3.684 \times 10^{5}$ & 710 \\
\hline cellulose & 0 & $5.906 \times 10^{5}$ & 1138 \\
& 1 & $5.475 \times 10^{5}$ & 1055 \\
& 3 & $5.065 \times 10^{5}$ & 976 \\
& 5 & $4.458 \times 10^{5}$ & 859 \\
& 7 & $4.255 \times 10^{5}$ & 820 \\
\hline
\end{tabular}

DP, degree of polymerization. 


\subsection{Cellulose Conversion Rate in Enzymatic Hydrolysis}

The cellulose conversion rate is the key parameter for evaluating enzymatic hydrolysis. Figure 10 shows the cellulose conversion rates in tunicate, $\alpha$-cellulose and amorphous cellulose samples. Compared with $\alpha$-cellulose and amorphous cellulose, the cellulose conversion rate of tunicate cellulose was extremely low. It was only $2.5 \%$ after $24 \mathrm{~h}$ of hydrolysis. After $96 \mathrm{~h}$, the maximum sugar conversion just reached $7.8 \%$, showing highly anti-enzymatic hydrolysis. However, for the case of $\alpha$-cellulose and amorphous cellulose, the cellulose conversion rates were relatively fast during the initial stage. After $12 \mathrm{~h}$, the rates were $52.8 \%$ and $97.0 \%$ for the $\alpha$-cellulose and amorphous cellulose, respectively. As indicated in Figure 10, after 96 h, the majority of $\alpha$-cellulose was hydrolyzed, and the cellulose conversion rate reached as high as $84.2 \%$. However, the amorphous cellulose was completely hydrolyzed after $24 \mathrm{~h}$. The variations of cellulose conversion rates between the tunicate, $\alpha$ - and amorphous celluloses are in agreement with the Mw and DP data in Table 1. The tunicate cellulose with high $\mathrm{CrI}$ had good stability and the highest ability of anti-enzymatic hydrolysis [57,58]. The most vulnerable one, amorphous cellulose, showed the lowest ability of anti-biodegradation, and it was completely hydrolyzed in a short period [59]. The ability of anti-biodegradation of the $\alpha$-cellulose was in between the tunicate and pure amorphous cellulose, since it contained both the amorphous and crystal regions in the cellulose structure.

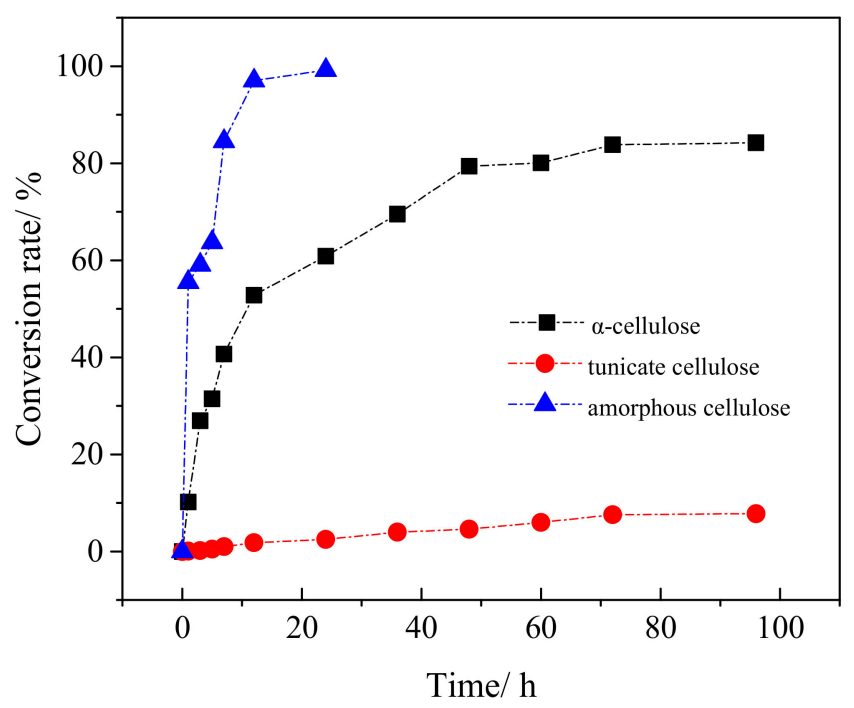

Figure 10. The cellulose conversion from various crystalline celluloses during enzymatic hydrolysis.

\subsection{TEM Analysis of Cellulose Nanocrystals}

Figure 11 shows the TEM images of tunicate cellulose and $\alpha$-cellulose nanocrystals. The length and width were calculated for tunicate nanocrystals (Figure 11a) and are $1.3 \mu \mathrm{m}$ and $20 \mathrm{~nm}$, respectively. The length-to-width ratio is 65 , which is close to the literature data [3]. Similarly, the length and width calculated for $\alpha$-cellulose nanocrystal (Figure 11b) are $300 \mathrm{~nm}$ and $20 \mathrm{~nm}$, respectively, and the length-to-width ratio is 10.5, which is also close to the previous report [34]. From this morphology analysis, it is shown that the length-to-width ratio for tunicate cellulose is much higher than for $\alpha$-cellulose, indicating its high mechanical strength $[3,60]$. 


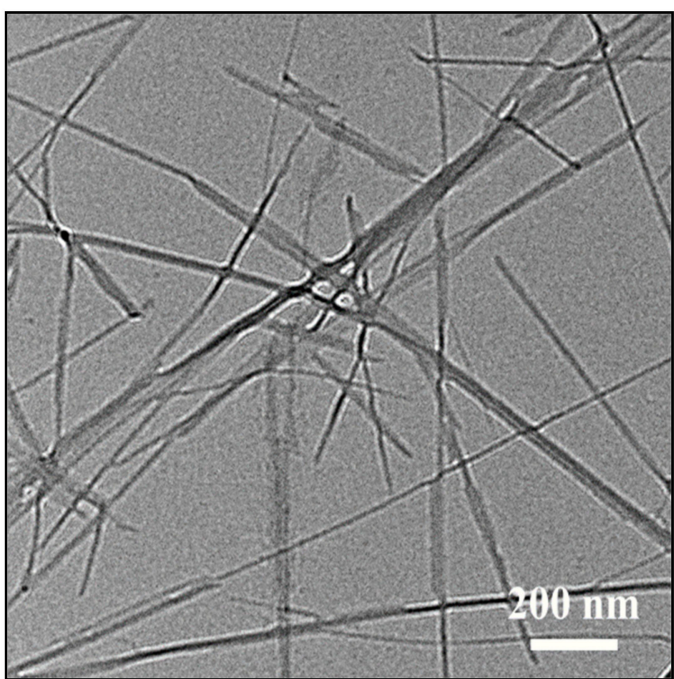

(a)

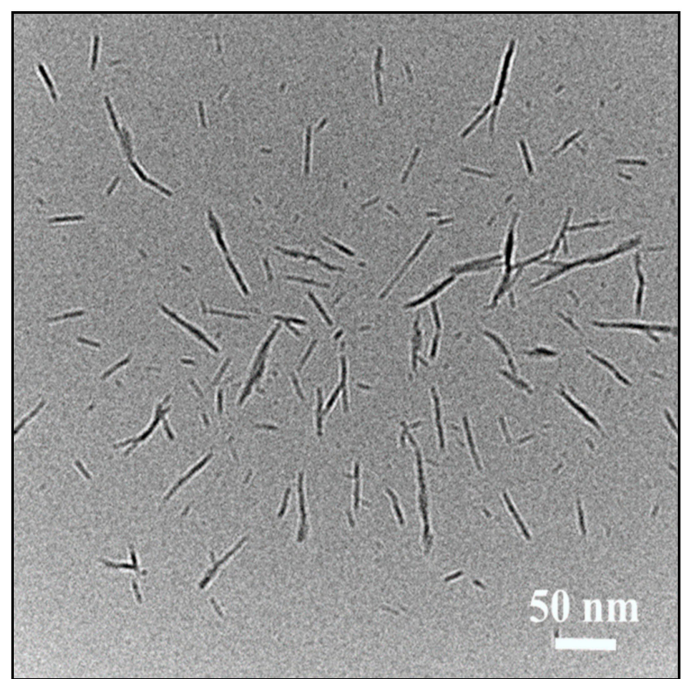

(b)

Figure 11. TEM images of (a) tunicate cellulose nanocrystals and (b) $\alpha$-cellulose nanocrystal.

\subsection{Anti-Mold Effects of Tunicate and $\alpha$-Cellulose Nanocrystals}

As discussed earlier, in Section 2.2.6, in order to evenly disperse the tunicate and $\alpha$-cellulose in the Martin agar medium, these two celluloses were hydrolyzed into nanocrystals by $\mathrm{H}_{2} \mathrm{SO}_{4}$, prior to the anti-mold experiment. Table 3 showed the variations of $\mathrm{CrI}$ of tunicate and $\alpha$-celluloses before and after the acid hydrolysis. After the acid hydrolysis, the decrease of $\mathrm{CrI}$ was only $4.2 \%$ and $5.8 \%$ for the tunicate and $\alpha$-celluloses, respectively. This indicated the acid hydrolysis had limit influences on the $\mathrm{CrI}$ of these two celluloses.

Table 3. The variations of $C r I$ of tunicate and $\alpha$-celluloses before and after the acid hydrolysis.

\begin{tabular}{ccc}
\hline & Before & After \\
\hline Tunicate cellulose & 93.9 & 90.0 \\
$\alpha$-cellulose & 74.3 & 70.0 \\
\hline
\end{tabular}

The mold growth rates of the blank sample, tunicate and $\alpha$-cellulose nanocrystals are represented in Figure 12. It is clearly shown the mold growth rate in the blank sample was much higher than that of tunicate and $\alpha$-celluloses. This was reasonable since the blank sample consisted of only the agar medium that was perfect for the mold cultivation. In addition, during the mold cultivation, the tunicate cellulose showed slower growth rate than the $\alpha$-cellulose. At $36 \mathrm{~h}$, the mold growth rate of tunicate cellulose was only $54.5 \%$ and $66.7 \%$ of the blank sample and the $\alpha$-cellulose, respectively. The anti-mold effect of the tunicate cellulose was remarkable. This is due to the fact that the highly crystalized $\mathrm{I}_{\beta}$ lattice in the tunicate cellulose has high anti-biodegrading abilities. However, the $\alpha$-cellulose contained both the amorphous and $\mathrm{I}_{\alpha}$ crystal regions, which were less resistant to the bio-degradation, as compared with the tunicate cellulose. It should be noted that the mold growth rate was faster during the first $36 \mathrm{~h}$ of cultivation, and it was then followed by a gradual decrease in the subsequent experiment (Figure 12). This is due to the that, for the mold growth cycles, the mold grows fast and turns to mature in the first $36 \mathrm{~h}$; then the mycelium growth gradually decreases. Consequently, the rate of mold growth reduced after $36 \mathrm{~h}$ of cultivation [61]. 


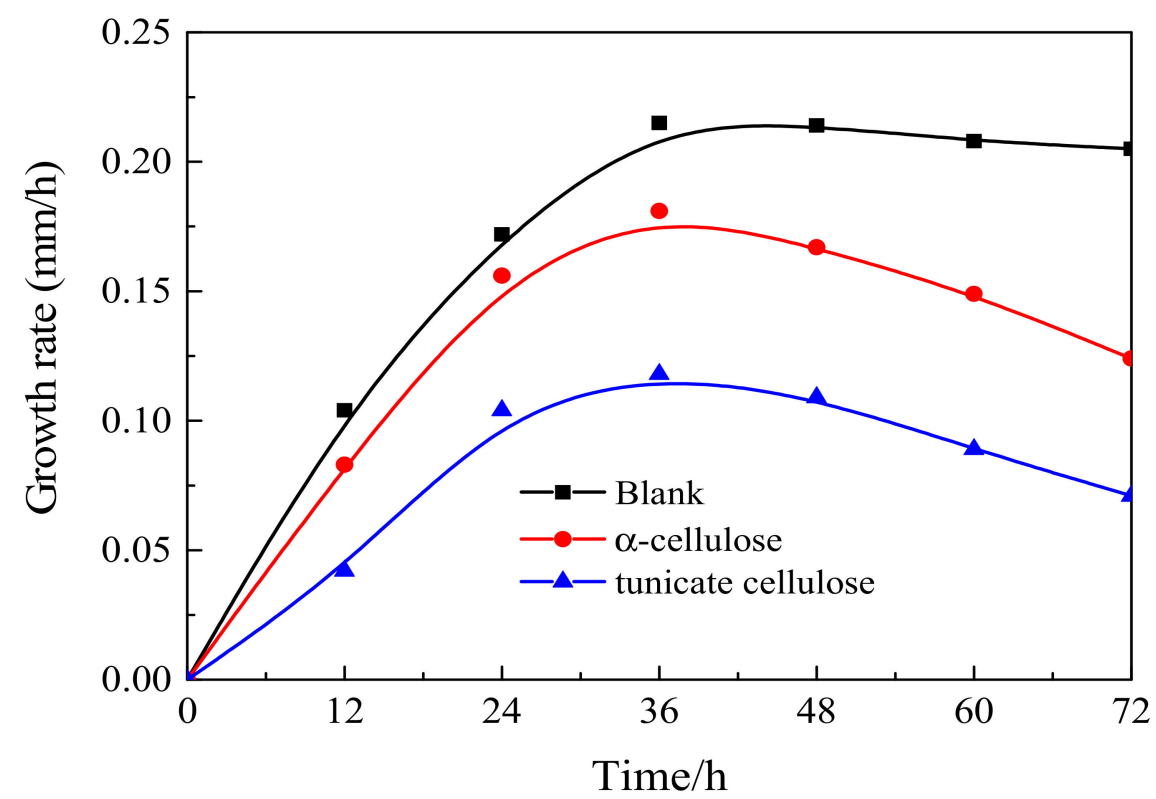

Figure 12. Anti-mold effect of tunicate cellulose nanocrystals and $\alpha$-cellulose nanocrystals.

\subsection{Measurement of Mold Growth Rate in the Medium Containing Various Amounts of Tunicate Nanocrystals}

Figure 13 shows the growth rate of mold in the medium containing various amounts of tunicate nanocrystals. The concentration of the tunicate nanocrystals used in this experiment was $1.4 \%$. In the mold cultivation, the tunicate cellulose was mixed in Martin medium by different dry weights, i.e., $0 \%$, $10 \%, 30 \%, 50 \%, 80 \%$ and 100\%. As shown in Figure 13, with the increase of tunicate nanocrystals in the medium, the mold growth rate decreased significantly. At $36 \mathrm{~h}$, the growth rate in the medium containing $80 \%$ of tunicate nanocrystals was $23.5 \%$ and $55.9 \%$ of the medium containing $10 \%$ and $50 \%$ of nanocrystals, respectively. It clearly shows that, the higher the content of tunicate nanocrystals in the medium, the slower mold growth rate during the cultivation. In addition, in the case that medium was only pure tunicate nanocrystals (medium containing 100\% of tunicate nanocrystals), there was no trace of mold growth during the $96 \mathrm{~h}$ of cultivation. As a result, the mold growth rate line in the case was flat, and the value was zero. This finding indicated that the tunicate had excellent anti-mold ability, and this ability was proportional to its content in the medium. As discussed earlier in the paper, tunicate cellulose consists of almost-pure $\mathrm{I}_{\beta}$ cellulose. The XRD measurement indicated that the crystallinity of tunicate cellulose is $93.9 \%$. This significantly high crystallinity renders the tunicate cellulose high in anti-biodegradation to the micro-organisms, as shown in the enzymatic hydrolysis experiment and these mold cultivation tests. The anti-mold properties of tunicate nanocrystals might have great potentials in the manufacturing of anti-biodegradation package and biomedical materials. 


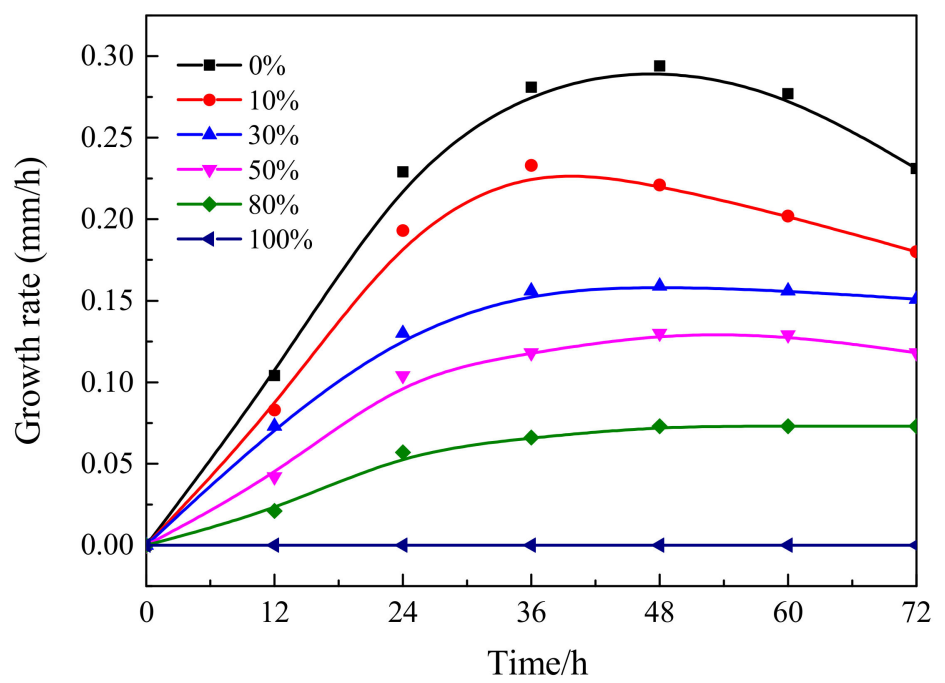

Figure 13. Antibacterial effect of different concentrations of tunicate cellulose nanocrystals.

\section{Conclusions}

Tunicate is different from other natural cellulose sources because it is the only animal species that generates cellulose in external tissues, contains a highly crystalized $\mathrm{I}_{\beta}$ lattice and has good anti-biodegradation properties. In this research, we studied the enzymatic hydrolysis and anti-biodegradation properties of different types of celluloses, namely tunicate cellulose, $\alpha$-cellulose and amorphous cellulose. Prepared tunicate cellulose was highly crystalline, had a large crystal size and had a high value of DP. XRD analysis exposed that the CrI of prepared tunicate cellulose and $\alpha$-cellulose was $93.9 \%$ and $70.9 \%$, respectively. Typical characteristic FTIR transmittance peaks of prepared different celluloses indicated that tunicate cellulose, $\alpha$-cellulose and amorphous cellulose contained $\mathrm{I}_{\beta}, \mathrm{I}_{\alpha}$ and amorphous phase of cellulose, respectively. After enzymatic hydrolysis of cellulose with the cellulase enzyme, it was found that the crystal structure of tunicate cellulose builds a physical barrier to prevent the attack of enzymes, and after $96 \mathrm{~h}$ of hydrolysis, its crystal lattice was intact; however, for $\alpha$-cellulose, the amorphous region was attacked by the enzyme. During enzymatic hydrolysis of tunicate cellulose, due to its unique monoclinic $\mathrm{I}_{\beta}$ crystal cell structure, the $\mathrm{CrI}$ fluctuated between $93.2 \%$ and $94.9 \%$, and the crystalline size $\left(I_{h k l}\right)$ was unchanged. The $M_{w}$ and DP are higher for tunicate cellulose, owing to its highly crystalline structure, which was almost unchanged during the enzymatic hydrolysis. However, amorphous cellulose was easily attacked by the enzyme, and after $7 \mathrm{~h}$ of hydrolysis, the DP decreased about $27.9 \%$. It was further proved by cellulose conversion rate that the maximum cellulose conversion rate for tunicate cellulose and $\alpha$-cellulose after $96 \mathrm{~h}$ enzymatic hydrolysis were $7.8 \%$ and $84.2 \%$, respectively. After $12 \mathrm{~h}$ of hydrolysis, the amorphous cellulose was almost totally $(97.0 \%)$ converted to sugar by the enzyme. TEM images proved that the length-to-width ratio of tunicate cellulose nanocrystals was higher (65) than $\alpha$-cellulose nanocrystal (10.5), indicating high mechanical strength. Tunicate cellulose had excellent antibacterial ability, and its highly crystalized $\mathrm{I}_{\beta}$ lattice strongly prohibited attacks from bacteria; as a result, the growth rate of mold was zero when the medium contained $100 \%$ tunicate cellulose nanocrystals. Due to its excellent resistance to micro-organisms, the tunicate cellulose could be potentially applied as renewable and anti-biodegradation materials.

Author Contributions: Conceptualization, investigation and funding acquisition, F.H.; writing-review and editing, Y.C. and A.K.M.; supervision, Y.N.; and methodology, data curation and writing-original draft, S.W., D.X. and D.N. All authors have read and agreed to the published version of the manuscript.

Funding: National Key Research and Development Program of China (2017YFB0307900), National Natural Science Foundation of China (22078061), the guide project from Department of Science and Technology of Fujian Province (2018H0006), and the Foundation (KF201922) of State Key Laboratory of Biobased Material and Green Papermaking, Qilu University of Technology, Shandong Academy of Sciences. 
Conflicts of Interest: The authors declare no conflict of interest.

\section{References}

1. Rojas, O.J. Cellulose Chemistry and Properties: Fibers, Nanocelluloses and Advanced Materials; Springer: Berlin/Heidelberg, Germany, 2016; Volume 271.

2. Zhao, Y.; Li, J. Excellent chemical and material cellulose from tunicates: Diversity in cellulose production yield and chemical and morphological structures from different tunicate species. Cellulose 2014, 21, 3427-3441. [CrossRef]

3. Habibi, Y.; Lucia, L.A.; Rojas, O.J. Cellulose nanocrystals: Chemistry, self-assembly, and applications. Chem. Rev. 2010, 110, 3479-3500. [CrossRef]

4. Schroers, M.; Kokil, A.; Weder, C. Solid polymer electrolytes based on nanocomposites of ethylene oxide-epichlorohydrin copolymers and cellulose whiskers. J. Appl. Polym. Sci. 2004, 93, 2883-2888. [CrossRef]

5. Mendez, J.D.; Weder, C. Synthesis, electrical properties, and nanocomposites of poly (3, 4-ethylenedioxythiophene) nanorods. Polym. Chem. 2010, 1, 1237-1244. [CrossRef]

6. Van den Berg, O.; Schroeter, M.; Capadona, J.R.; Weder, C. Nanocomposites based on cellulose whiskers and (semi) conducting conjugated polymers. J. Mater. Chem. 2007, 17, 2746-2753. [CrossRef]

7. Podsiadlo, P.; Sui, L.; Elkasabi, Y.; Burgardt, P.; Lee, J.; Miryala, A.; Kusumaatmaja, W.; Carman, M.R.; Shtein, M.; Kieffer, J. Layer-by-layer assembled films of cellulose nanowires with antireflective properties. Langmuir 2007, 23, 7901-7906. [CrossRef]

8. Zhu, G.; Xu, H.; Dufresne, A.; Lin, N. High-adsorption, self-extinguishing, thermal, and acoustic-resistance aerogels based on organic and inorganic waste valorization from cellulose nanocrystals and red mud. ACS Sustain. Chem. Eng. 2018, 6, 7168-7180. [CrossRef]

9. Biyani, M.V.; Foster, E.J.; Weder, C. Light-healable supramolecular nanocomposites based on modified cellulose nanocrystals. ACS Macro Lett. 2013, 2, 236-240. [CrossRef]

10. Fox, J.; Wie, J.J.; Greenland, B.W.; Burattini, S.; Hayes, W.; Colquhoun, H.M.; Mackay, M.E.; Rowan, S.J. High-strength, healable, supramolecular polymer nanocomposites. J. Am. Chem. Soc. 2012, 134, 5362-5368. [CrossRef]

11. Capadona, J.R.; Shanmuganathan, K.; Tyler, D.J.; Rowan, S.J.; Weder, C. Stimuli-responsive polymer nanocomposites inspired by the sea cucumber dermis. Science 2008, 319, 1370-1374. [CrossRef]

12. Kim, D.S.; Jung, S.-M.; Yoon, G.H.; Lee, H.C.; Shin, H.S. Development of a complex bone tissue culture system based on cellulose nanowhisker mechanical strain. Colloids Surf. B Biointerfaces 2014, 123, 838-844. [CrossRef] [PubMed]

13. American Chemical Society. Contaminants in Our Water: Identification and Remediation Methods; ACS Publications: Washington, DC, USA, 2020.

14. Mahfoudhi, N.; Boufi, S. Nanocellulose as a novel nanostructured adsorbent for environmental remediation: A review. Cellulose 2017, 24, 1171-1197. [CrossRef]

15. Thomas, B.; Raj, M.C.; Joy, J.; Moores, A.; Drisko, G.L.; Sanchez, C.m. Nanocellulose, a versatile green platform: From biosources to materials and their applications. Chem. Rev. 2018, 118, 11575-11625. [CrossRef] [PubMed]

16. Chen, W.; Yu, H.; Lee, S.-Y.; Wei, T.; Li, J.; Fan, Z. Nanocellulose: A promising nanomaterial for advanced electrochemical energy storage. Chem. Soc. Rev. 2018, 47, 2837-2872. [CrossRef]

17. Wang, L.; Zuo, X.; Raut, A.; Isseroff, R.; Xue, Y.; Zhou, Y.; Sandhu, B.; Schein, T.; Zeliznyak, T.; Sharma, P. Operation of proton exchange membrane (PEM) fuel cells using natural cellulose fiber membranes. Sustain. Energy Fuels 2019, 3, 2725-2732. [CrossRef]

18. Klemm, D.; Cranston, E.D.; Fischer, D.; Gama, M.; Kedzior, S.A.; Kralisch, D.; Kramer, F.; Kondo, T.; Lindström, T.; Nietzsche, S. Nanocellulose as a natural source for groundbreaking applications in materials science: Today's state. Mater. Today 2018, 21, 720-748. [CrossRef]

19. Christov, L.; Akhtar, M.; Prior, B. The potential of biosulfite pulping in dissolving pulp production. Enzym. Microb. Technol. 1998, 23, 70-74. [CrossRef]

20. Adney, B.; Baker, J. Measurement of Cellulase Activities: Laboratory Analytical Procedure (LAP); Technical Report; National Renewable Energy Laboratory (NREL): Golden, CO, USA, 2008.

21. Ouyang, J.; Dong, Z.; Song, X.; Lee, X.; Chen, M.; Yong, Q. Improved enzymatic hydrolysis of microcrystalline cellulose (Avicel PH101) by polyethylene glycol addition. Bioresour. Technol. 2010, 101, 6685-6691. [CrossRef] 
22. Park, S.; Baker, J.O.; Himmel, M.E.; Parilla, P.A.; Johnson, D.K. Cellulose crystallinity index: Measurement techniques and their impact on interpreting cellulase performance. Biotechnol. Biofuels 2010, 3, 10. [CrossRef]

23. Segal, L.; Creely, J.; Martin, A., Jr.; Conrad, C. An empirical method for estimating the degree of crystallinity of native cellulose using the X-ray diffractometer. Text. Res. J. 1959, 29, 786-794. [CrossRef]

24. Heinze, T.; Liebert, T. Unconventional methods in cellulose functionalization. Prog. Polym. Sci. 2001, 26, 1689-1762. [CrossRef]

25. Hubbell, C.A.; Ragauskas, A.J. Effect of acid-chlorite delignification on cellulose degree of polymerization. Bioresour. Technol. 2010, 101, 7410-7415. [CrossRef] [PubMed]

26. Cohen, R.; Jensen, K.A.; Houtman, C.J.; Hammel, K.E. Significant levels of extracellular reactive oxygen species produced by brown rot basidiomycetes on cellulose. Febs Lett. 2002, 531, 483-488. [CrossRef]

27. Tang, Y.; Yang, S.; Zhang, N.; Zhang, J. Preparation and characterization of nanocrystalline cellulose via low-intensity ultrasonic-assisted sulfuric acid hydrolysis. Cellulose 2014, 21, 335-346. [CrossRef]

28. Boriová, K.; Čerňanský, S.; Matúš, P.; Bujdoš, M.; Šimonovičová, A.; Urík, M. Removal of aluminium from aqueous solution by four wild-type strains of Aspergillus niger. Bioprocess Biosyst. Eng. 2019, 42, 291-296. [CrossRef] [PubMed]

29. Zhao, P.; Xia, W.; Lei, C.; Omer, S.H.; Zhang, X.; Zhuang, Y.; Chen, S. Isolation, Identification and Physiological Activity of Endophytes from the Roots of Vitis vinifera. Nanosci. Nanotechnol. Lett. 2016, 8, 532-538. [CrossRef]

30. Siede, W. A "Hole Punched Plate" method for easy generation and harvesting of microconidia in the dermatophyte Trichophyton rubrum. Heliyon 2018, 4, e00676. [CrossRef]

31. Haafiz, M.M.; Eichhorn, S.; Hassan, A.; Jawaid, M. Isolation and characterization of microcrystalline cellulose from oil palm biomass residue. Carbohydr. Polym. 2013, 93, 628-634. [CrossRef]

32. Abraham, E.; Deepa, B.; Pothan, L.; Jacob, M.; Thomas, S.; Cvelbar, U.; Anandjiwala, R. Extraction of nanocellulose fibrils from lignocellulosic fibres: A novel approach. Carbohydr. Polym. 2011, 86, 1468-1475. [CrossRef]

33. Kale, R.D.; Bansal, P.S.; Gorade, V.G. Extraction of microcrystalline cellulose from cotton sliver and its comparison with commercial microcrystalline cellulose. J. Polym. Environ. 2018, 26, 355-364. [CrossRef]

34. Zhao, Y.; Moser, C.; Lindström, M.E.; Henriksson, G.; Li, J. Cellulose nanofibers from softwood, hardwood, and tunicate: Preparation-structure-film performance interrelation. ACS Appl. Mater. Interfaces 2017, 9, 13508-13519. [CrossRef] [PubMed]

35. Trilokesh, C.; Uppuluri, K.B. Isolation and characterization of cellulose nanocrystals from jackfruit peel. Sci. Rep. 2019, 9, 1-8. [CrossRef] [PubMed]

36. Ibrahim, N.A.; Azraaie, N.; Abidin, Z.; Mohd, N.A.; Mamat Razali, N.A.; Abdul Aziz, F.; Zakaria, S. Preparation and characterization of alpha cellulose of pineapple (Ananas comosus) leaf fibres (PALF). In Advanced Materials Research; NREL: Golden, CO, USA, 2014; pp. 147-150.

37. Rivai, H.; Hamdani, A.S.; Ramdani, R.; Lalfari, R.S.; Andayani, R.; Armin, F.; Djamaan, A. Production and Characterization of Alpha Cellulose Derived From Rice Straw (Oryza sativa L.). Int. J. Pharm. Sci. Rev. Res. 2018, 52, 45-48.

38. Galiwango, E.; Rahman, N.S.A.; Al-Marzouqi, A.H.; Abu-Omar, M.M.; Khaleel, A.A. Isolation and characterization of cellulose and $\alpha$-cellulose from date palm biomass waste. Heliyon 2019, 5, e02937. [CrossRef]

39. Ju, X.; Bowden, M.; Brown, E.E.; Zhang, X. An improved X-ray diffraction method for cellulose crystallinity measurement. Carbohydr. Polym. 2015, 123, 476-481. [CrossRef]

40. Ciolacu, D.; Ciolacu, F.; Popa, V.I. Amorphous cellulose-Structure and characterization. Cellul. Chem. Technol. 2011, 45, 13.

41. Sugiyama, J.; Persson, J.; Chanzy, H. Combined infrared and electron diffraction study of the polymorphism of native celluloses. Macromolecules 1991, 24, 2461-2466. [CrossRef]

42. Rosa, M.; Medeiros, E.; Malmonge, J.; Gregorski, K.; Wood, D.; Mattoso, L.; Glenn, G.; Orts, W.; Imam, S. Cellulose nanowhiskers from coconut husk fibers: Effect of preparation conditions on their thermal and morphological behavior. Carbohydr. Polym. 2010, 81, 83-92. [CrossRef]

43. Popescu, M.-C.; Popescu, C.-M.; Lisa, G.; Sakata, Y. Evaluation of morphological and chemical aspects of different wood species by spectroscopy and thermal methods. J. Mol. Struct. 2011, 988, 65-72. [CrossRef]

44. Poletto, M.; Pistor, V.; Zeni, M.; Zattera, A.J. Crystalline properties and decomposition kinetics of cellulose fibers in wood pulp obtained by two pulping processes. Polym. Degrad. Stab. 2011, 96, 679-685. [CrossRef] 
45. Zhao, Y.; Zhang, Y.; Lindström, M.E.; Li, J. Tunicate cellulose nanocrystals: Preparation, neat films and nanocomposite films with glucomannans. Carbohydr. Polym. 2015, 117, 286-296. [CrossRef] [PubMed]

46. Szymanska-Chargot, M.; Zdunek, A. Use of FT-IR spectra and PCA to the bulk characterization of cell wall residues of fruits and vegetables along a fraction process. Food Biophys. 2013, 8, 29-42. [CrossRef] [PubMed]

47. Fengel, D.; Wegener, G. Wood: Chemistry, ultrastructure. Reactions 1984, 613, 1960-1982.

48. Teeri, T.T. Crystalline cellulose degradation: New insight into the function of cellobiohydrolases. Trends Biotechnol. 1997, 15, 160-167. [CrossRef]

49. Fan, L.; Gharpuray, M.; Lee, Y.H. Evaluation of pretreatments for enzymatic conversion of agricultural residues. In Proceedings of the Symposium on Biotechnology in Energy Production and Conservation, Gatlinburg, TN, USA, 12 May 1981.

50. Li, Q.; Qi, W.; Su, R.; He, Z. Enhanced enzymatic hydrolysis and changes in structure of cellulose regenerated with ionic liquids. Cellul. Chem. Technol. 2017, 51, 593-600.

51. Sasaki, T.; Tanaka, T.; Nanbu, N.; Sato, Y.; Kainuma, K. Correlation between X-ray diffraction measurements of cellulose crystalline structure and the susceptibility to microbial cellulase. Biotechnol. Bioeng. 1979, 21, 1031-1042. [CrossRef]

52. Sinitsyn, A.; Gusakov, A.; Vlasenko, E.Y. Effect of structural and physico-chemical features of cellulosic substrates on the efficiency of enzymatic hydrolysis. Appl. Biochem. Biotechnol. 1991, 30, 43-59. [CrossRef]

53. Nishiyama, Y.; Langan, P.; Chanzy, H. Crystal structure and hydrogen-bonding system in cellulose I $\beta$ from synchrotron X-ray and neutron fiber diffraction. J. Am. Chem. Soc. 2002, 124, 9074-9082. [CrossRef]

54. Zhu, L.; O'Dwyer, J.P.; Chang, V.S.; Granda, C.B.; Holtzapple, M.T. Structural features affecting biomass enzymatic digestibility. Bioresour. Technol. 2008, 99, 3817-3828. [CrossRef] [PubMed]

55. Yuan, T.Q.; Wang, W.; Zhang, L.M.; Xu, F.; Sun, R.C. Reconstitution of cellulose and lignin after [C2mim][OAc] pretreatment and its relation to enzymatic hydrolysis. Biotechnol. Bioeng. 2013, 110, 729-736. [CrossRef]

56. Yang, B.; Dai, Z.; Ding, S.-Y.; Wyman, C.E. Enzymatic hydrolysis of cellulosic biomass. Biofuels 2011, 2, 421-449. [CrossRef]

57. Huang, Y.-B.; Fu, Y. Hydrolysis of cellulose to glucose by solid acid catalysts. Green Chem. 2013, 15, $1095-1111$. [CrossRef]

58. Hsu, T.-C.; Guo, G.-L.; Chen, W.-H.; Hwang, W.-S. Effect of dilute acid pretreatment of rice straw on structural properties and enzymatic hydrolysis. Bioresour. Technol. 2010, 101, 4907-4913. [CrossRef]

59. Kafle, K.; Shin, H.; Lee, C.M.; Park, S.; Kim, S.H. Progressive structural changes of Avicel, bleached softwood and bacterial cellulose during enzymatic hydrolysis. Sci. Rep. 2015, 5, 1-10. [CrossRef] [PubMed]

60. Sacui, I.A.; Nieuwendaal, R.C.; Burnett, D.J.; Stranick, S.J.; Jorfi, M.; Weder, C.; Foster, E.J.; Olsson, R.T.; Gilman, J.W. Comparison of the properties of cellulose nanocrystals and cellulose nanofibrils isolated from bacteria, tunicate, and wood processed using acid, enzymatic, mechanical, and oxidative methods. ACS Appl. Mater. Interfaces 2014, 6, 6127-6138. [CrossRef] [PubMed]

61. Adams, T.H.; Wieser, J.K.; Yu, J.-H. Asexual sporulation in Aspergillus nidulans. Microbiol. Mol. Biol. Rev. 1998, 62, 35-54. [CrossRef]

Publisher's Note: MDPI stays neutral with regard to jurisdictional claims in published maps and institutional affiliations.

(C) 2020 by the authors. Licensee MDPI, Basel, Switzerland. This article is an open access article distributed under the terms and conditions of the Creative Commons Attribution (CC BY) license (http://creativecommons.org/licenses/by/4.0/). 